\title{
Desenvolvimento e produtividade de grãos de milho submetido a níveis de desfolha
}

\author{
Wender Santos Rezende(1), Césio Humberto de Brito(1), Afonso Maria Brandão(2), Cláudio José Faria Franco(2), \\ Maurício Viana Ferreira(2) e Adão de Siqueira Ferreira(1)
}

(1)Universidade Federal de Uberlândia, Instituto de Ciências Agrárias, Avenida Amazonas, s/no, Umuarama, CEP $38400-902$ Uberlândia, MG, Brasil. E-mail: wendersrezende@gmail.com, cesiohumberto@iciag.ufu.br, adaoferreira@iciag.ufu.br (2)Syngenta Seeds, BR 452, Km 142,5, CEP 38405-232 Uberlândia, MG, Brasil. E-mail: afonso.brandao@syngenta.com, claudio.franco@syngenta.com, mauricio.ferreira@syngenta.com

Resumo - O objetivo deste trabalho foi avaliar a influência da desfolha do milho no desenvolvimento e na produtividade de grãos. Seis ensaios foram conduzidos em diferentes safras e locais e em dois níveis de produtividade. Utilizou-se o delineamento de blocos ao acaso, com sete repetições. A desfolha foi realizada no estádio vegetativo $\mathrm{V}_{4}$ do milho (quatro folhas expandidas), e os tratamentos foram: remoção das duas folhas basais, remoção das quatro folhas expandidas, remoção total das folhas (secção da parte aérea) e testemunha (sem desfolha). Foram avaliados: duração do período vegetativo; e, em pré-colheita, altura de planta, altura de espiga, percentagem de plantas acamadas, força de quebramento de colmo, força de arranquio da planta e produtividade. A remoção das quatro folhas e a remoção total aumentaram a duração do período vegetativo e reduziram a altura de planta, a altura de espiga e a resistência do colmo ao quebramento. Esses níveis de desfolha também reduziram a produtividade, principalmente com a remoção total das folhas. A força de arranquio da planta não foi influenciada pela desfolha. A retirada de quatro folhas e do total das folhas reduz a produtividade de grãos, respectivamente, em 6,25 a 14,05\% nos híbridos avaliados.

Termos para indexação: Zea mays, área foliar, integridade foliar, período vegetativo, potencial produtivo.

\section{Grain development and yield in maize subjected to defoliation levels}

\begin{abstract}
The objective of this work was to evaluate the influence of defoliation of maize on grain development and yield. Six trials were conducted in different growing seasons and locations and at two yield levels. A randomized complete block design was used, with seven replicates. Defoliation was made at the $\mathrm{V}_{4}$ vegetative stage of maize (four expanded leaves), and treatments consisted of: removal of the two basal leaves, removal of the four expanded leaves, total removal of leaves (aerial plant section), and a control (without defoliation). The following were evaluated: length of the vegetative period; and, at pre-harvest, plant height, ear insertion height, plant lodging percentage, stalk-breaking strength, force required to pull the plant, and yield. The removal of four leaves and the total removal of leaves increased the length of the vegetative period and reduced plant height, ear insertion height, and stalk strength against breaking. These defoliation levels also reduced yield, mainly with the total removal of leaves. The force required to pull the plant was not influenced by defoliation. Removal of four leaves and of all leaves reduces grain yield, respectively, in 6.25 to 14,05 in the evaluated hybrids.
\end{abstract}

Index terms: Zea mays, leaf area, leaf integrity, vegetative period, yield potential.

\section{Introdução}

O potencial produtivo da cultura do milho (Zea mays L.) é definido por volta dos estádios $\mathrm{V}_{4}$ e $\mathrm{V}_{5}$, de quatro a cinco folhas expandidas, respectivamente, em razão da diferenciação floral (Ritchie et al., 1993). Nesse período, a planta origina os primórdios do pendão e da espiga, e também ocorre a diferenciação de todas as folhas (Ritchie et al., 1993). No estádio $\mathrm{V}_{5}$, o meristema apical ainda está abaixo da superfície do solo, o que permite a recuperação da planta dos danos causados na parte aérea (Ritchie et al., 1993; Magalhães \& Durães, 2006). No estádio $\mathrm{V}_{8}$, define-se o número de fileiras de grãos e, posteriormente, o número de óvulos por fileira até o estádio $\mathrm{V}_{17}$ (Magalhães \& Durães, 2006).

O período crítico da cultura do milho estende-se da pré-floração até o início do enchimento de grãos, uma 
vez que ocorrências de estresses, como deficit hídrico e redução da área foliar, têm grande impacto sobre a produção (Bergamaschi et al., 2004; Brito et al., 2011). Com a definição do potencial da cultura, o início do ciclo também se torna um período crítico. Logo, a ocorrência de condições ótimas nessa fase, como manutenção da área foliar, é um fator importante para a produção.

Apesar da evolução das técnicas de manejo, da resistência genética e da biotecnologia terem contribuído para a sanidade e o desempenho da cultura do milho, muitos estresses bióticos e abióticos que comumente ocorrem no início do ciclo da cultura, como, por exemplo, ataque de nematoides, competição com plantas infestantes, ataque de percevejos, chuva de granizo, vento e geada, podem causar danos severos, principalmente pela redução da atividade fotossintética (Levy et al., 2009; Torres et al., 2013).

A manutenção da integridade foliar é importante, pois a folha é o principal órgão responsável pela fotossíntese; além disso, a cultura apresenta baixa capacidade de compensar as perdas foliares, já que sua prolificidade, capacidade efetiva de compensação de espaços e plasticidade foliar são reduzidas (Strieder et al., 2007; Pereira et al., 2012).

Entretanto, alguns autores afirmam que a desfolha decorrente de chuva de granizo, geada ou vento nos estádios iniciais do milho tem pouco ou nenhum efeito sobre a produtividade da cultura (Ritchie et al., 1993; Magalhães \& Durães, 2006). Assim, é essencial compreender o impacto dos estresses, como a desfolha, no início do ciclo, para o planejamento ideal do manejo da cultura.

O objetivo deste trabalho foi avaliar a influência da desfolha realizada no estádio vegetativo $\mathrm{V}_{4}$ do milho no desenvolvimento e na produtividade de grãos.

\section{Material e Métodos}

Foram realizados seis ensaios em campo, em diferentes safras e locais e em dois níveis de produtividade. Na safra 2011/2012, foram realizados quatro ensaios: dois em Uberlândia, $\mathrm{MG}$, com semeadura em 19/11/2011; e dois em Coromandel, MG, com semeadura em 4/12/2011. Na safra 2012/2013, foram realizados dois ensaios em Coromandel, MG, com semeadura em 26/10/2012. Todos os ensaios foram realizados em sistema de semeadura direta. Em cada ambiente (combinação de ano e local), foram realizados dois ensaios, um de alta produtividade e outro de média produtividade.

Os ensaios em Uberlândia $\left(19^{\circ} 05^{\prime} 40^{\prime \prime} \mathrm{S}, 48^{\circ} 08^{\prime} 19^{\prime \prime} \mathrm{W}\right.$, a $954 \mathrm{~m}$ de altitude) foram realizados em condições de sequeiro. O local apresenta temperatura anual média de $22,8^{\circ} \mathrm{C}$, precipitação anual média de $1.493 \mathrm{~mm}$ e clima Aw, tropical com estação seca no inverno, de acordo com a classificação de Köppen. Os ensaios em Coromandel (19 $36^{\prime} 13^{\prime \prime S}$, 46 ${ }^{\circ} 53^{\prime} 37^{\prime \prime} \mathrm{W}$, a $1.131 \mathrm{~m}$ de altitude) foram realizados sob irrigação via pivô central. O local apresenta temperatura anual média de $21,8^{\circ} \mathrm{C}$, precipitação anual média de $1.644 \mathrm{~mm}$ e clima Aw, conforme a classificação de Köppen. Em Coromandel, os ensaios das diferentes safras foram realizados em áreas adjacentes. $\mathrm{O}$ solo de ambos os locais avaliados é classificado como Latossolo Vermelho-Amarelo. Os atributos químicos do solo foram determinados na camada de 0 a $20 \mathrm{~cm}$ (Tabela 1). Em todas as áreas, cultivou-se soja na safra anterior e utilizou-se nabo forrageiro para cobertura de solo durante a entressafra.

Nos dois níveis de produtividade, em todos os ambientes, foi utilizada uma população composta por dois híbridos simples de alto potencial produtivo (NB7253 e NB7205), e o manejo buscou a expressão desse potencial. No nível de produtividade alto, com população média de 86.000 plantas por hectare, utilizou-se a adubação total de $220 \mathrm{~kg} \mathrm{ha}^{-1}$ de $\mathrm{N}$, $100 \mathrm{~kg} \mathrm{ha}^{-1}$ de $\mathrm{P}_{2} \mathrm{O}_{5}$ e $160 \mathrm{~kg} \mathrm{ha}^{-1}$ de $\mathrm{K}_{2} \mathrm{O}$. No nível de produtividade médio, com população média de 66.000 plantas por hectare, utilizou-se adubação total de $176 \mathrm{~kg} \mathrm{ha}^{-1}$ de $\mathrm{N}, 80 \mathrm{~kg} \mathrm{ha}^{-1}$ de $\mathrm{P}_{2} \mathrm{O}_{5}$ e $128 \mathrm{~kg} \mathrm{ha}^{-1}$ de $\mathrm{K}_{2} \mathrm{O}$.

Para todos os ensaios, utilizou-se o delineamento de blocos ao acaso, com quatro tratamentos - compostos por níveis de desfolha - e sete repetições. A desfolha foi realizada manualmente no estádio vegetativo $V_{4}$ do milho, 15 a 20 dias após a emergência. Nesse estádio, a planta apresenta-se com quatro folhas completamente expandidas, segundo Ritchie et al. (1993), e com mais duas em desenvolvimento. Os tratamentos foram: remoção das duas folhas basais, remoção das quatro folhas completamente expandidas, remoção total das folhas (secção da parte aérea), além de uma testemunha (sem desfolha). No tratamento com remoção total, foram removidas quatro folhas completamente expandidas e mais duas folhas que ainda não estavam totalmente expandidas. Para tanto, a secção da parte aérea foi realizada entre a segunda e a terceira folhas, tendo-se cortado a planta com uma tesoura. Após o 
corte da planta, restaram a primeira e a segunda folhas, que foram retiradas manualmente. As parcelas foram constituídas por seis linhas de 4,2 m espaçadas em 0,6 m. A área útil de cada parcela foi constituída pelas quatro linhas centrais, o que totalizou $10,08 \mathrm{~m}^{2}$.

Foi mensurada a área foliar a partir de duas plantas por repetição de cada tratamento, em cada ambiente. As plantas foram ensacadas, identificadas e armazenadas para posterior avaliação. As folhas separadas das plantas foram digitalizadas com uso de impressora HP Photosmart D110 (HP Brasil, Barueri, SP). Em seguida, a área $\left(\mathrm{cm}^{2}\right)$ de cada folha foi determinada por meio do programa Quant, versão 1.0.1. (Vale et al., 2001). A medida da área foliar retirada de cada tratamento foi obtida a partir da média das plantas retiradas dos seis experimentos (Tabela 2).

Foram avaliados: a duração do período vegetativo; e, em pré-colheita (estádio $\mathrm{R}_{6}$ ), a altura de planta, a altura de inserção da espiga principal, a percentagem de plantas acamadas, a força de quebramento de colmo, a força de arranquio da planta e a produtividade de grãos.

A duração do período vegetativo compreendeu o número de dias entre a emergência e o espigamento, quando os estilo-estigmas de $50 \%$ das plantas da parcela emergiram para fora da espiga. Nos dias próximos ao florescimento, a presença dos estilo-estigmas na parte externa da espiga foi avaliada visual e diariamente, em cada parcela.

Tabela 1. Resultados das análises químicas de solo, na camada de 0 a $20 \mathrm{~cm}$, nos diferentes locais avaliados, nas safras 2011/2012 e 2012/2013.

\begin{tabular}{|c|c|c|c|}
\hline Propriedades & $\begin{array}{l}\text { Uberlândia } \\
\text { 2011/2012 }\end{array}$ & $\begin{array}{c}\text { Coromandel } \\
2011 / 2012\end{array}$ & $\begin{array}{c}\text { Coromandel } \\
2012 / 2013\end{array}$ \\
\hline $\mathrm{pH} \mathrm{em} \mathrm{H}_{2} \mathrm{O}$ & 5,4 & 5,7 & 5,5 \\
\hline P-Mehlich $1\left(\mathrm{mg} \mathrm{dm}^{-3}\right)$ & 25,1 & 18,2 & 15,1 \\
\hline $\mathrm{K}^{+}\left(\mathrm{mg} \mathrm{dm}^{-3}\right)$ & 105,0 & 145,0 & 132,7 \\
\hline $\mathrm{Ca}^{2+}\left(\mathrm{cmol}_{\mathrm{c}} \mathrm{dm}^{-3}\right)$ & 1,8 & 2,3 & 2,4 \\
\hline $\mathrm{Mg}^{2+}\left(\mathrm{cmol}_{\mathrm{c}} \mathrm{dm}^{-3}\right)$ & 0,5 & 0,7 & 0,8 \\
\hline $\mathrm{Al}^{3+}\left(\mathrm{cmol}_{\mathrm{c}} \mathrm{dm}^{-3}\right)$ & 0,1 & 0,0 & 0,0 \\
\hline $\mathrm{H}+\mathrm{Al}\left(\mathrm{cmol}_{\mathrm{c}} \mathrm{dm}^{-3}\right)$ & 2,2 & 3,6 & 3,6 \\
\hline MO (dag kg-1) & 2,7 & 3,4 & 3,4 \\
\hline $\mathrm{SB}\left(\mathrm{cmol}_{\mathrm{c}} \mathrm{dm}^{-3}\right)$ & 2,6 & 3,4 & 3,5 \\
\hline $\mathrm{t}\left(\mathrm{cmol}_{\mathrm{c}} \mathrm{dm}^{-3}\right)$ & 2,7 & 3,4 & 3,5 \\
\hline $\mathrm{T}\left(\mathrm{cmol}_{\mathrm{c}} \mathrm{dm}^{-3}\right)$ & 4,8 & 7,0 & 7,1 \\
\hline V $(\%)$ & 54,2 & 48,4 & 49,3 \\
\hline $\mathrm{m}(\%)$ & 3,7 & 0,0 & 0,0 \\
\hline Argila $\left(\mathrm{g} \mathrm{kg}^{-1}\right)$ & 505,0 & 411,0 & 408,0 \\
\hline
\end{tabular}

Para a avaliação da altura de plantas, determinouse o comprimento de três plantas representativas da parcela, tendo-se considerado como limite superior da planta a inserção da primeira ramificação do pendão. Nas mesmas plantas, mediu-se a altura de inserção da espiga principal.

Para a avaliação da percentagem de plantas acamadas, foi determinado o estande da parcela e o número de plantas acamadas; posteriormente, calculou-se a percentagem que as plantas acamadas representavam na parcela. Consideraram-se como plantas acamadas aquelas que, em pré-colheita, estavam tombadas ou com o colmo quebrado abaixo da espiga.

A força necessária ao quebramento do colmo foi avaliada em dez plantas sequenciais de uma linha da parcela útil com uso do aparelho inclinômetro, equipado com dinamômetro. Utilizou-se o método descrito por Gomes et al. (2010), que consiste em aplicar força transversal ao colmo na altura da espiga principal, com auxílio de uma corda, até o ponto de ruptura da planta. Ao romper-se o colmo, o dinamômetro registra a força necessária ao quebramento.

A força necessária ao arranquio da planta foi avaliada em dez plantas sequenciais de uma linha da parcela útil com uso do aparelho arrancômetro, constituído por uma base de sustentação, uma manivela, um sistema de roldanas, uma garra e um dinamômetro. Utilizouse o método descrito por Gomes et al. (2010), que consiste em exercer a força vertical necessária para arrancar a planta. O sistema de roldanas distribui a força necessária ao arranquio em quatro partes, e o dinamômetro quantifica uma dessas partes. Para o cálculo da força total necessária ao arranquio da planta, aplicou-se a equação $F=F d \times 4$, em que $F$ é a força total, em kgf; e Fd é a força medida pelo dinamômetro, também em kgf.

Tabela 2. Área foliar removida de cada tratamento no estádio $\mathrm{V}_{4}$ da cultura do milho (Zea mays).

\begin{tabular}{lccc}
\hline Nível de desfolha & $\begin{array}{c}\text { Área foliar } \\
\text { retirada } \\
\left(\mathrm{cm}^{2}\right)\end{array}$ & $\begin{array}{c}\text { Área foliar } \\
\text { remanescente } \\
\left(\mathrm{cm}^{2}\right)\end{array}$ & $\begin{array}{c}\text { Percentagem } \\
\text { de desfolha } \\
(\%)\end{array}$ \\
\hline Sem desfolha & 0,00 & 65,66 & 0,00 \\
Duas folhas removidas & 9,04 & 58,26 & 13,43 \\
Quatro folhas removidas & 45,33 & 18,07 & 71,50 \\
Remoção total (seç̧ão) & 68,20 & 0,00 & 100,00 \\
\hline
\end{tabular}


A colheita foi realizada com uma colhedora automotriz, adaptada para colheita de parcelas. O peso e a umidade foram determinados por um sistema de balança e por um determinador de umidade, ambos instalados na colhedora. A produtividade foi obtida a partir dos valores de pesos das parcelas, transformados para $\mathrm{kg} \mathrm{ha}^{-1}$, com umidade corrigida para $13 \%$. A partir dos dados de produtividade, calculou-se a redução relativa da produtividade de cada nível de desfolha em relação ao tratamento testemunha (sem desfolha).

Os dados obtidos foram submetidos à análise da variância, pelo teste $\mathrm{F}$, a $5 \%$ de probabilidade. Realizou-se análise conjunta dos ambientes para cada nível de produtividade (médio e alto), exceto para a redução relativa da produtividade, para a qual se realizou análise conjunta, tanto com os ambientes quanto com os níveis de produtividade. Considerouse, para as análises conjuntas, que as razões entre o maior e o menor quadrado médio do resíduo, para todas as caraterísticas avaliadas, foram menores que 7 . As médias foram comparadas pelo teste de Tukey, a $5 \%$ de probabilidade.

\section{Resultados e Discussão}

Nos dois níveis de produtividade, não houve interação entre tratamentos e ambientes quanto às características avaliadas. A remoção das duas folhas basais não alterou a duração do período vegetativo da cultura, a altura de planta e a altura de espiga (Tabela 3). A remoção de duas folhas ocasionou menor estresse à planta, pois foram retiradas as duas folhas menores, que representavam $13,4 \%$ da área foliar total da planta (Tabela 2), e menos expostas à luminosidade durante o restante do ciclo.

Tanto em condições de média produtividade quanto de alta produtividade, a retirada de quatro folhas atrasou o início do período reprodutivo em 1,9 e 1,3 dias, respectivamente; já com a remoção total (secção da planta), o atraso foi de 4 e 4,4 dias, respectivamente. Fasae et al. (2009) observaram que a retirada da metade da área foliar após 4 semanas da semeadura, período similar ao avaliado no presente trabalho, atrasou o início do período reprodutivo em 3 a 5 dias. Hussain et al. (2013) avaliaram o estresse na cultura do milho decorrente da competição com Xanthium strumarium e verificaram que, quanto maior a população dessa planta infestante, maior foi o atraso no início do período reprodutivo do milho.
A remoção de quatro folhas reduziu a altura de planta, e a remoção total levou à maior redução da altura em ambos os níveis de produtividade (Tabela 3 ). A altura de inserção da espiga foi reduzida com a remoção de quatro folhas no nível de produtividade alto e, principalmente, com a remoção total, em ambos os níveis de produtividade. Com esses tratamentos, a área fotossintética da planta foi consideravelmente reduzida, o que diminuiu a disponibilidade de fotoassimilados para o seu crescimento. No caso da remoção total, houve um curto período com área fotossinteticamente ativa reduzida e com gasto energético para a planta rebrotar, o que prejudicou todo o seu desenvolvimento. Khaliliaqdam et al. (2012) também constataram redução na altura de planta e na altura de inserção da espiga, em decorrência de desfolhas realizadas entre os estádios $\mathrm{V}_{6}$ e $\mathrm{V}_{8}$ da cultura do milho. Além disso, observaram que, quanto maior foi a área foliar removida, menor foi a altura de planta e a altura de inserção de espiga, semelhantemente ao verificado no presente trabalho.

Não foram observadas diferenças significativas nas percentagens de plantas acamadas entre os tratamentos avaliados, em ambos os níveis de produtividade (Tabela 4). Contudo, houve redução

Tabela 3. Análise conjunta dos locais avaliados (Uberlândia e Coromandel, MG) quanto às características duração do período vegetativo (DPV), altura de planta e altura de inserção da espiga, com a desfolha realizada no estádio vegetativo $\mathrm{V}_{4}$ do milho (Zea mays), para os níveis de produtividade médio e alto, nas safras 2011/2012 e 2012/2013 ${ }^{(1)}$.

\begin{tabular}{|c|c|c|c|}
\hline Nível de desfolha & $\begin{array}{l}\text { DPV } \\
\text { (dias) }\end{array}$ & $\begin{array}{l}\text { Altura de } \\
\text { planta (m) }\end{array}$ & $\begin{array}{l}\text { Altura de } \\
\text { espiga (m) }\end{array}$ \\
\hline & \multicolumn{3}{|c|}{ Nível de produtividade médio } \\
\hline Sem desfolha & $70,0 \mathrm{a}$ & $2,30 \mathrm{a}$ & $1,33 \mathrm{a}$ \\
\hline Duas folhas removidas & $70,3 \mathrm{a}$ & $2,26 \mathrm{ab}$ & $1,32 \mathrm{a}$ \\
\hline Quatro folhas removidas & $71,9 b$ & $2,24 b$ & $1,30 \mathrm{a}$ \\
\hline$\underline{\text { Remoção total (secção) }}$ & $74,0 \mathrm{c}$ & $2,18 \mathrm{c}$ & $1,16 \mathrm{~b}$ \\
\hline \multirow[t]{2}{*}{ CV $(\%)$} & 0,7 & 1,3 & 5,0 \\
\hline & \multicolumn{3}{|c|}{ Nível de produtividade alto } \\
\hline Sem desfolha & $69,0 \mathrm{a}$ & $2,43 a$ & $1,41 \mathrm{a}$ \\
\hline Duas folhas removidas & $69,0 \mathrm{a}$ & $2,39 \mathrm{ab}$ & $1,38 \mathrm{ab}$ \\
\hline Quatro folhas removidas & $70,3 b$ & $2,35 b$ & $1,33 \mathrm{bc}$ \\
\hline Remoção total (secção) & $73,4 \mathrm{c}$ & $2,30 \mathrm{c}$ & $1,30 \mathrm{c}$ \\
\hline $\mathrm{CV}(\%)$ & 0,5 & 2,6 & 6,3 \\
\hline
\end{tabular}

${ }^{(1)}$ Médias seguidas de letras iguais, nas colunas, não diferem pelo teste de Tukey, a $5 \%$ de probabilidade. 
da força de quebramento do colmo com a remoção total das folhas. A menor área foliar e a consequente menor taxa fotossintética prejudicaram a estrutura do colmo durante o período vegetativo, o que o deixou menos resistente ao quebramento. Karam et al. (2010) concluíram que danos causados pelo corte ou pela maceração em plantas de milho nos estádios $\mathrm{V}_{2}$ e $\mathrm{V}_{4}$ reduzem o acúmulo de biomassa do colmo.

Apesar de não ter havido diferença na percentagem de plantas acamadas entre os tratamentos, a redução na força de quebramento é uma indicação de que, em condição adversa, como na ocorrência de ventos fortes, a desfolha pode tornar as plantas mais suscetíveis ao quebramento. O quebramento de colmo prejudica a colheita mecanizada e pode até inviabilizá-la, com perdas de produção em lavoura de milho.

De acordo com Gomes et al. (2010), a força de arranquio da planta é uma medida utilizada para a avaliação da resistência das plantas de milho ao acamamento. No presente trabalho, observou-se que a desfolha não influenciou a força necessária ao arranquio da planta (Tabela 4), o que indica que, mesmo que a desfolha tenha afetado o desenvolvimento radicular, não houve influência sobre a resistência da planta ao

Tabela 4. Análise conjunta dos locais avaliados (Uberlândia e Coromandel, MG) quanto às características percentagem de plantas acamadas, força necessária ao quebramento do colmo e força necessária ao arranquio da planta, com a desfolha realizada no estádio vegetativo $\mathrm{V}_{4}$ do milho (Zea mays), para os níveis de produtividade médio e alto, nas safras 2011/2012 e 2012/2013 ${ }^{(1)}$.

\begin{tabular}{lccc}
\hline Nível de desfolha & $\begin{array}{c}\text { Plantas } \\
\text { acamadas } \\
(\%)\end{array}$ & $\begin{array}{c}\text { Força de } \\
\text { quebramento } \\
(\mathrm{kgf})\end{array}$ & $\begin{array}{c}\text { Força de } \\
\text { arranquio } \\
(\mathrm{kgf})\end{array}$ \\
\hline Sem desfolha & \multicolumn{3}{c}{ Nível de produtividade médio } \\
Duas folhas removidas & $0,11 \mathrm{a}$ & $1,35 \mathrm{ab}$ & $30,49 \mathrm{a}$ \\
Quatro folhas removidas & $0,35 \mathrm{a}$ & $1,33 \mathrm{ab}$ & $36,35 \mathrm{a}$ \\
Remoção total (secção) & $0,32 \mathrm{a}$ & $1,13 \mathrm{~b}$ & $36,59 \mathrm{a}$ \\
\hline CV (\%) & 165,3 & 11,2 & 16,1 \\
\hline & \multicolumn{3}{c}{ Nível de produtividade alto } \\
Sem desfolha & $0,00 \mathrm{a}$ & $1,38 \mathrm{a}$ & $28,41 \mathrm{a}$ \\
Duas folhas removidas & $0,32 \mathrm{a}$ & $1,39 \mathrm{a}$ & $29,56 \mathrm{a}$ \\
Quatro folhas removidas & $0,08 \mathrm{a}$ & $1,24 \mathrm{a}$ & $27,74 \mathrm{a}$ \\
Remoção total (seç̃ão) & $0,33 \mathrm{a}$ & $1,00 \mathrm{~b}$ & $20,81 \mathrm{a}$ \\
\hline CV (\%) & 262,9 & 11,5 & 19,0 \\
\hline
\end{tabular}

${ }^{(1)}$ Médias seguidas de letras iguais, nas colunas, não diferem pelo teste de Tukey, a 5\% de probabilidade. acamamento. Embora haja relatos de que a desfolha aumenta a alocação de recursos para o crescimento da parte aérea, em detrimento do crescimento da raiz (Todorovic et al., 1999; Yang \& Midmore, 2004), não há estudos que mostrem correlação entre o desenvolvimento radicular e a força de arranquio da planta.

A remoção de duas folhas não influenciou a produtividade dos grãos (Figura 1). No nível de produtividade alto, a remoção de quatro folhas reduziu a produtividade em $4,5 \%$, e a secção da planta reduziu a produtividade em $12,1 \%$. No nível de produtividade médio, a retirada de quatro folhas reduziu a produtividade em $8 \%$, e a secção da planta, em $16 \%$.

Independentemente do nível de produtividade e do ambiente avaliado, a remoção total das folhas provocou maior redução da produtividade do que a retirada de quatro folhas (Tabela 5). Em todos os ambientes avaliados, no nível de produtividade médio, houve maior impacto da desfolha sobre a produtividade do que no nível alto. Isso pode ser atribuído à grande densidade de plantas no nível alto, maior do que a densidade utilizada comumente na cultura do milho.

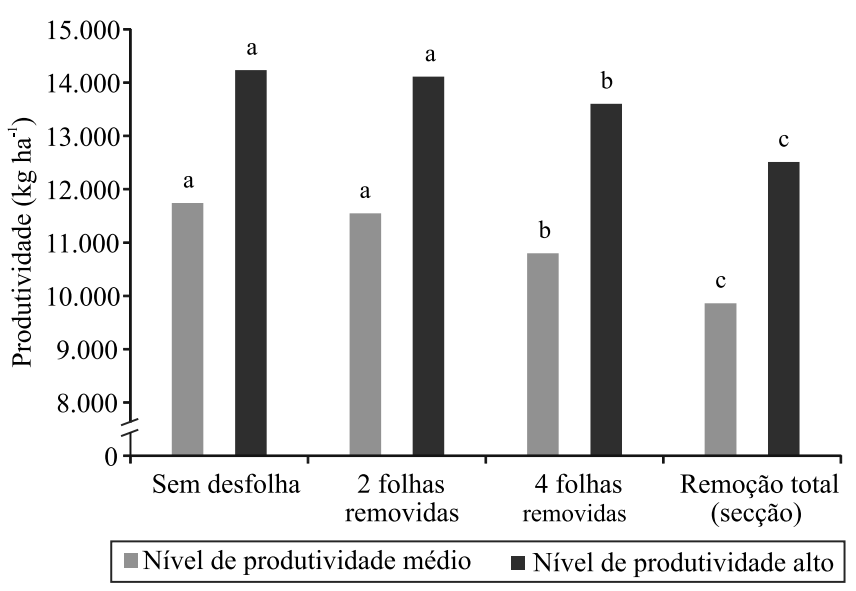

Figura 1. Análise conjunta dos locais avaliados (Uberlândia e Coromandel, MG) quanto à característica produtividade de grãos em função do nível de desfolha realizada no estádio vegetativo $\mathrm{V}_{4}$ do milho (Zea mays), para os níveis de produtividade médio e alto, nas safras 2011/2012 e 2012/2013. Médias seguidas de letras iguais, em cada nível de produtividade, não diferem pelo teste de Tukey, a 5\% de probabilidade. Os coeficientes de variação da característica produtividade de grãos para os níveis de produtividade médio e alto foram de 6,3 e 5,1\%, respectivamente. 
Assim, em razão do alto índice de área foliar (IAF) no nível de produtividade alto, a redução no IAF com a desfolha pode não ter sido tão limitante quanto no nível de produtividade médio.

A desfolha ocorreu no período de definição do potencial produtivo da cultura, em que a menor disponibilidade de fotoassimilados para a planta pode ter prejudicado essa definição, com menor potencial produtivo. Baldo (2007) observou que plantas de milho cobertas por sombrite $50 \%$, entre os estádios $V_{2}$ e $\mathrm{V}_{5}$, sofreram estresse por luz e tiveram redução de $17 \%$ em seu potencial produtivo. Karam et al. (2010) constataram reduções de 29 a $42 \%$ na produtividade de grãos de milho com o corte da planta, respectivamente, nos estádios $\mathrm{V}_{2}$ e $\mathrm{V}_{4}$.

Os resultados do presente trabalho são indicativos de que, mesmo havendo um longo período para a planta se recuperar da desfolha, isso não ocorreu de forma efetiva, diferentemente do relatado por outros autores em trabalhos anteriores (Magalhães \& Durães, 2006; Pearson \& Fletcher, 2009; Pereira et al., 2012; Sangoi et al., 2014). Contudo, no presente trabalho, as médias de produtividade foram superiores às obtidas por esses autores, o que indica que, em lavouras nas quais se almejem altos tetos produtivos, pequenas perdas de área foliar, nos estádios iniciais de desenvolvimento, afetam significativamente a produtividade. É possível que a análise conjunta de três ensaios para cada nível de produtividade, realizada no presente trabalho, mas não nos estudos prévios, tenha contribuído para a detecção

Tabela 5. Análise conjunta dos locais avaliados (Uberlândia e Coromandel, MG) quanto à redução da produtividade em relação ao tratamento sem desfolha, para os demais tratamentos e para os níveis de produtividade médio e alto, nas safras 2011/2012 e 2012/2013 ${ }^{(1)}$.

\begin{tabular}{lc}
\hline Tratamento & Redução da produtividade (\%) \\
\hline Número de folhas removidas & $1,40 \mathrm{a}$ \\
Duas folhas & $6,25 \mathrm{~b}$ \\
Quatro folhas & $14,05 \mathrm{c}$ \\
Remoção total (secção) & \\
\hline Nível de produtividade & $8,55 \mathrm{a}$ \\
Médio & $5,89 \mathrm{~b}$ \\
Alto & 68,29 \\
\hline $\mathrm{CV}(\%)$ & \\
${ }^{(1)}$ Médias seguidas de letras iguais, nas colunas, em cada fator (tratamento \\
e nível de produtividade), não diferem pelo teste de Tukey, a 5\% de \\
probabilidade. ${ }^{(2)}$ Redução relativa da produtividade em relação ao \\
tratamento testemunha (sem desfolha).
\end{tabular}

de diferenças estatísticas pelos testes utilizados. Além disso, como os ensaios foram realizados em diferentes ambientes, pode-se afirmar que a desfolha acima de quatro folhas exerce impacto importante na produtividade do milho; portanto, a resposta do milho depende, também, do nível tecnológico utilizado.

\section{Conclusões}

1. A retirada de quatro folhas e do total das folhas no estádio vegetativo $\mathrm{V}_{4}$ da cultura do milho (Zea mays) prejudica o crescimento da planta e atrasa o início do período reprodutivo.

2. A retirada de quatro folhas e do total das folhas reduz a produtividade de grãos respectivamente em 6,25 a $14,05 \%$ nos híbridos avaliados.

\section{Agradecimentos}

À Coordenação de Aperfeiçoamento de Pessoal de Nível Superior (Capes), pela concessão de bolsa; e à Syngenta Seeds, pelo apoio financeiro e estrutural.

\section{Referências}

BALDO, M.N. Comportamento anatômico, fisiológico e agronômico do milho (Zea mays $\mathbf{L}$.) submetido a estresses de ambiente em diferentes estádios fenológicos. 2007. 92p. Dissertação (Mestrado) - Universidade de São Paulo, Piracicaba.

BERGAMASCHI, H.; DALMAGO, G.A.; BORGONCI, J.I.; BIANCHI, C.A.M.; MÜLLER, A.G.; COMIRAN, F.; HECKLER, B.M.M. Distribuição hídrica no período crítico do milho e produção de grãos. Pesquisa Agropecuária Brasileira, v.39, p.831-839, 2004. DOI: $10.1590 / \mathrm{S} 0100-204 X 2004000900001$.

BRITO, C.H. de; SILVEIRA, D.L.; BRANDÃO, A.M.; GOMES, L.S.; LOPES, M.T.G. Redução de área foliar em milho em região tropical no Brasil e os efeitos em caracteres agronômicos. Interciencia, v.36, p.291-295, 2011

FASAE, O.A.; ADU, F.I.; AINA, A.B.J.; ELEMO, K.A. Effects of defoliation time of maize on leaf yield, quality and storage of maize leafs as dry season forage for ruminant production. Revista Brasileira de Ciências Agrárias, v.4, p.353-357, 2009. DOI: 10.5039/agraria.v4i3a19.

GOMES, L.S.; BRANDÃO, A.M.; BRITO, C.H. de; MORAES, D.F. de; LOPES, M.T.G. Resistência ao acamamento de plantas e ao quebramento do colmo em milho tropical. Pesquisa Agropecuária Brasileira, v.45, p.140-145, 2010. DOI: 10.1590/ S0100-204X2010000200004.

HUSSAIN, Z.; MARWAT, K.B.; KHAN, M.A.; HASHIM, S.; BAKHT, T. How the competition of Xanthium strumarium L. affects the phonological characters of maize crop. Pakistan Journal of Botany, v.45, p.1883-1887, 2013. 
KARAM, D.; PEREIRA FILHO, I.A.; MAGALHÃES, P.C.; PAES, M.C.D.; SILVA, J.A.A.; GAMA, J. de C.M. Resposta de plantas de milho à simulação de danos mecânicos. Revista Brasileira de Milho e Sorgo, v.9, p.201-211, 2010.

KHALILIAQDAM, N.; SOLTANI, A.; MIR-MAHMOODI, T.; JADIDI, T. Effect of leaf defoliation on some agronomical traits of corn. World Applied Sciences Journal, v.20, p.545-548, 2012. DOI: 10.5829/idosi.wasj.2012.20.04.2498.

LEVY, R.M.; HOMECHIN, M.; SANTIAGO, D.C.; CADIOLI, M.C.; BAIDA, F.C. Reação de genótipos de milho ao parasitismo de Meloidogyne incognita raça 1 e a $M$. paranaensis. Acta Scientiarum. Agronomy, v.31, p.575-578, 2009. DOI: 10.4025/ actasciagron.v31i4.761.

MAGALHÃES, P.C.; DURÃES, F.O.M. Fisiologia da produção de milho. Sete Lagoas: Embrapa Milho e Sorgo, 2006. 10p. (Embrapa Milho e Sorgo. Circular técnica, 76).

PEARSON, A.; FLETCHER, A.L. Effect of total defoliation on maize growth and yield. Agronomy New Zealand, v.39, p.1-6, 2009.

PEREIRA, M.J.R.; BONAN, E.C.B.; GARCIA, A.; VASCONCELOS, R. de L.; GIACOMO, K. dos S.; LIMA, M.F. Características morfoagronômicas do milho submetido a diferentes níveis de desfolha manual. Revista Ceres, v.59, p.200-205, 2012. DOI: 10.1590/S0034-737X2012000200008.

RITCHIE, S.W.; HANWAY, J.J.; BENSON, G.O. How a corn plant develops. Ames: Iowa State University of Science and Technology, 1993. 26p. (Special report, 48).
SANGOI, L.; PICOLI JUNIOR, G.J.; VARGAS, V.P.; VIEIRA, J.; SCHMITT, A.; ZOLDAN, S.R.; SIEGA, E.; CARNIEL, G. Cobertura nitrogenada como estratégia para reduzir os prejuízos da desfolha em diferentes estádios fenológicos do milho. Semina: Ciências Agrárias, v.35, p.671-682, 2014. DOI: 10.5433/1679-0359.2014v35n2p671.

STRIEDER, M.L.; SILVA, P.R.F. da; ARGENTA, G.; RAMBO, L.; SANGOI, L.; SILVA, A.A. da; ENDRIGO, P.C. A resposta do milho irrigado ao espaçamento entrelinhas depende do híbrido e da densidade de plantas. Ciência Rural, v.37, p.634-642, 2007. DOI: 10.1590/S0103-84782007000300006.

TODOROVIC, C.; NGUYEN, C.; ROBIN, C.; GUCKERT, A. ${ }^{14} \mathrm{C}$-assimilate partitioning within white clover plant-soil system: effects of photoperiod/temperature treatments and defoliation. European Journal of Agronomy, v.11, p.13-21, 1999. DOI: 10.1016/S1161-0301(99)00004-0.

TORRES, A.B.A.; OLIVEIRA, N.C. de; OLIVEIRA NETO, A.M. de; GUERREIRO, J.C. Injúrias causadas pelo ataque dos percevejos marrom e barriga verde durante o desenvolvimento inicial do milho. Journal of Agronomic Sciences, v.2, p.169-177, 2013.

VALE, F.X.R.; FERNANDES FILHO, E.I.; LIBERATO, J.R. QUANT: quantificação de doenças. Versão 1.0.1. Viçosa: Ed. da UFV, 2001.

YANG, Z.; MIDMORE, D.J. Experimental assessment of the impact of defoliation on growth and production of water-stressed maize and cotton plants. Experimental Agriculture, v.40, p.189-199, 2004. DOI: 10.1017/S0014479703001534. 